\title{
Robotic Duodenal Switch Is Associated with Outcomes Comparable to those of Laparoscopic Approach
}

\author{
Ahmed M. Al-Mazrou ${ }^{1}$ (D) $\cdot$ Mariana Vigiola Cruz ${ }^{1} \cdot$ Gregory Dakin $^{1} \cdot$ Omar E. Bellorin-Marin ${ }^{1} \cdot$ Alfons Pomp $^{1}$. \\ Cheguevara Afaneh ${ }^{1}$
}

Received: 16 September 2020 / Revised: 20 December 2020 / Accepted: 29 December 2020 / Published online: 18 January 2021

(C) The Author(s), under exclusive licence to Springer Science+Business Media, LLC part of Springer Nature 2021

\begin{abstract}
Introduction/Purpose This study evaluates the outcomes of robotic duodenal switch (RDS) when compared to conventional laparoscopy (LDS).

Materials and Methods Using the Metabolic and Bariatric Surgery Accreditation and Quality Improvement Program (MBSAQIP), patients who underwent RDS were compared to those of LDS (2015-2018) for perioperative characteristics and thirty-day postoperative outcomes. Operative complexity, complications, and resource utilization trends were plotted over the included years for the two approaches. Multivariable analysis was conducted to characterize the impact of each approach on these outcomes.

Results Of 7235 minimally invasive operations, 5720 (79.1\%) were LDS while 1515 (20.9\%) were RDS. Intraoperative endoscopy, anastomosis testing, and shorter operative duration were associated with LDS. RDS group had more concomitant procedures with less attending assistance. The odds ratios of organ space infection and sepsis were equivalent. RDS increased the odds ratios for venous thromboembolism [VTE] (odds ratio $[\mathrm{OR}]=2.3,95 \%$ confidence interval $[\mathrm{CI}]=1.1-4.8, p=0.02$ ) and early discharge $(\mathrm{OR}=7.3, \mathrm{CI}=4.9-10.9, p<0.01)$. The difference in wound infection between LDS and RDS has been decreasing ( $1.5 \%$ and $1.5 \%$ in 2018 from $2.3 \%$ and $4.1 \%$ in 2015 , respectively) over the years. Similarly, the decreasing trends were noted for systemic infections.

Conclusion While the development of VTE after RDS was higher, most of the other complications were comparable between LDS and RDS in this study. RDS may reduce the need for advanced intraoperative assistance and minimize hospital stay in select cases, without increasing morbidity. The recent trends suggest a gradual decrease in the variations between LDS and RDS outcomes over time.
\end{abstract}

Keywords Duodenal switch $\cdot$ Laparoscopic $\cdot$ Robotic $\cdot$ Outcomes $\cdot$ Trends

\section{Introduction}

Bariatric surgery carries specific challenges given the nature of the patient population. The patients' thicker abdominal wall, increased visceral fat, and larger foregut organs are

Meeting Presentation Podium presentation, the Scientific Forum at the Clinical Congress of the American College of Surgeons, Chicago, IL, USA, October, 4-7, 2020.

Cheguevara Afaneh cha9043@med.cornell.edu

1 Division of GI Metabolic and Bariatric Surgery, Department of Surgery, New York-Presbyterian Hospital/Weill Cornell Medicine, 525 East 68th Street Box 294, New York, NY 10065, USA common intraoperative obstacles. This is particularly important in cases that are considered technically challenging, such as the duodenal switch [1,2].

Several studies have demonstrated the ability of minimally invasive techniques to help overcome some of these barriers [3-6]. In addition to shorter hospital stay, the robotic approach has been shown to reduce readmission when compared to laparoscopy after Roux-en-Y gastric bypass [6]. Furthermore, the technology was found to have lower costs comparing to conventional open and laparoscopic gastric bypass when morbidity was included in the analyses [7].

The initial duodenal switch series have reported the rates of anastomotic leak to be 9\% [8] and 8\% [9] for laparoscopic and robotic approaches, respectively. However, the complication has been demonstrated to be less than $1 \%$ for both platforms 
by other and recent analyses [10-13]. As the operating time decreased for minimally invasive duodenal switch, the occurrence of postoperative venous thrombosis has been shown to be minimized over time $[9,11,13,14]$. Some robotic duodenal switch case series found shorter hospital stay [12, 13], comparing to conventional laparoscopy (LDS) institutional experiences $[8,14]$. Despite the lack of a comparative assessment, prior institutional reports have supported the safety of LDS and robotic duodenal switch (RDS) given low postoperative mortality $[9,10,15]$.

However, it is unclear whether the introduction of robotic surgery has improved the performance of duodenal switch. The literature lacks a comparative evaluation of the outcomes after LDS and RDS. In addition, an assessment of how RDS outcomes may be changing as the learning curve flattens in robotic surgery is not yet characterized. In this study, using the multicenter Metabolic and Bariatric Surgery Accreditation and Quality Improvement Program (MBSAQIP) data, the outcomes of LDS and RDS were compared. A secondary aim was to characterize the trends in outcomes between the two approaches over years (2015-2018).

\section{Material and Methods}

Patients who underwent LDS or RDS (primary Current Procedural Terminology [CPT] code: 43845, pyloruspreserving partial gastrectomy with duodenoileostomy and ileoileostomy - 50 to 100 common channel) were included from the MBSAQIP between 2015 and 2018. The MBSAQIP is a large and representative national database that collects bariatrics-specific information using standardized definitions. The database collects de-identified patient-level information from more than 850 participating hospitals. Additional information on the database can be found elsewhere [16]. The study did not involve animal or human subjects. The MBSAQIP data collection and utilization were approved by the ethical committees at the New YorkPresbyterian Hospital/Weill Cornell Medical Center. Informed consent was not required in this study.

Perioperative parameters were compared between LDS and RDS including patient demographics, comorbidities, history of bariatric surgery, and body mass index (BMI). Intraoperative information including the level of required skilled surgical assistance, concurrent procedures performed, unplanned conversion to open surgery, and operative duration were also evaluated. The first assistant was classified as the intraoperative presence of a secondary attending (bariatrictrained or other surgeons), fellow or resident, physician assistant, nurse practitioner, or registered nurse. Prolonged operation was defined as any operative duration beyond the median time for all duodenal switch operations, which was $139 \mathrm{~min}$. The median time included the duration of open, laparoscopic, and robotic cases performed between 2015 and 2018 from the database. Revisional surgery was defined as any case in which the patient had a history of prior bariatric surgery. Converted operations to other types of metabolic procedures were also captured under the same variable. Thirty-day postoperative surgical and medical complications compared between the two groups included organ space infection, systemic infection (sepsis), and venous thromboembolism. Organ space infection was defined as an infection that involves any part of the anatomy other than the incision, which was opened or manipulated during an operation within 30 days after surgery. Sepsis was defined as the presence of any two signs of systemic inflammatory response syndrome (SIRS) within 30 days after surgery, including the following: temperature $>38^{\circ} \mathrm{C}$ or $<$ $36{ }^{\circ} \mathrm{C}, \mathrm{HR}>90 \mathrm{bpm}, \mathrm{RR}>20$ breaths $/ \mathrm{min}$ or $\mathrm{PaCO}_{2}<$ $32 \mathrm{mmHg}, \mathrm{WBC}>12,000$ or $<4000 \mathrm{cell} / \mathrm{mm}^{3}$, and anion gap acidosis. Given the feasibility of same-day discharge [17], early discharge was defined as postoperative hospital stay of less than $24 \mathrm{~h}$ after surgery. Mortality was defined as any intraoperative or postoperative death within 30 days from surgery.

Resource utilization parameters including hospital stay, intensive care unit (ICU) admission, readmission, and reoperation within 30 days after surgery, as well as extended care after discharge were similarly evaluated. Extended care after discharge was defined as any placement to skilled or unskilled nursing facility, rehabilitation center, or another acute-care hospital. Univariable and multivariable analyses were conducted to compare outcomes between the two platforms. Patient complexity factors such as the American Society of Anesthesiologist (ASA) class 3-4, BMI $\geq 40$ and operative revision were plotted over the included years (2015-2018) for the two groups. The variation in 30-day postoperative morbidity between laparoscopic and robotic duodenal switch over time was also characterized, including surgical site infections, sepsis/septic shock, venous thromboembolism, and bleeding requiring transfusion. The trends of resource utilization, including 30-day postoperative reoperation, readmission, ICU admission, and postoperative length of stay, were plotted for the two techniques.

\section{Statistical Analysis}

Categorical and continuous variables were illustrated by frequency $(n)$ - percentage $(\%)$ and median (interquartile range, IQR) - mean (standard deviation, SD) respectively. The statistical significance was evaluated by chi-square for categorical variables while nonparametric test and $t$ test for continuous factors. Certain perioperative variables were dichotomized to simplify data demonstration, such as age $(<65$ versus $\geq$ 65 years), patient's baseline functional dependence (partial and total dependence versus independence), and operative duration ( $<140$ versus $\geq 140 \mathrm{~min}$ ). Due to limited observations, 
cardiac comorbidities (history of prior myocardial infarction, cardiac surgery, or percutaneous cardiac intervention) were grouped as a single variable. Given the nature of the disease process, venous thromboembolism variable was created by combining deep vein thrombosis and pulmonary embolism. Several new variables were created including upper endoscopy, paraesophageal hernia repair, and cholecystectomy using secondary CPT codes.

The independent association between the two platforms and 30-day postoperative organ space infection, sepsis, venous thromboembolism, and early discharge (length of stay $[\mathrm{LOS}]<24 \mathrm{~h}$ ) was assessed by multivariable analyses. Variables with $p$ value $<0.05$ in the univariable analyses were considered statistically significant and candidates for the inclusion in the multivariable analyses. Age, race, presence of preoperative gastroesophageal reflux disease, baseline functional dependence, body mass index, limited preoperative ambulation, preoperative hemoglobin and albumin levels, intraoperative level of assistance required, anastomotic testing, use of intraoperative upper endoscopy, performance of concurrent paraesophageal hernia repair and/or cholecystectomy, and prolonged operation were adjusted in the logistic regression models. The differences between LDS and RDS with respect to patient complexity (age, ASA class 3-4, BMI $\geq 40$, and operative revision), 30-day postoperative complications, and resource utilization were compared in each year. The variations in these outcomes between the two approaches were plotted across years (2015-2018). Few variables had missing data, including age, BMI, operative duration, proactive testing of anastomosis, and postoperative dehydration. The missing observations were clinically and statistically insignificant. The statistical analysis was conducted using SAS 9.4 (SAS Institute Inc., Cary, NC).

\section{Results}

Of 7235 duodenal switch operations, 5720 (79.1\%) were LDS and 1515 (20.9\%) were RDS. While ASA classes were equivalent between the included patients in the two groups, older age (mean [SD], years: 44 [11.4] vs. 43 [10.7], $p=0.01$ ) and white race $(79.9 \%$ vs. $72.5 \%, p<0.01)$ represented a greater proportion in LDS group. Despite the higher weights in LDS group (mean [SD], kg: 136.6 [50.3] vs. 132.9 [56.1], $p=$ 0.01 ), RDS cases had greater BMI averages (mean [SD]: 50.8 [9.4] vs. 51.8 [10.1], $p=0.004)$. Operative revision and pre-existing comorbidities were comparable between the two groups, with the exception of higher rates of gastroesophageal reflux disease $(30.9 \%$ vs. $25 \%, p<0.01)$ in the LDS group. Patients in the LDS cohort were more likely to be functionally dependent with limited ambulation (Table 1). In the analysis of operative factors (Table 2), the rate of conversion to open surgery was equivalent. The use of the robotic platform was associated with a higher rate of concurrent operations (paraoesophageal hernia: $10.4 \%$ vs. $8.7 \%, p=0.04$; cholecystectomy: $14.1 \%$ vs. $6.2 \%, p<0.01)$ compared to laparoscopy. LDS operations were noted to require a higher level of intraoperative advanced assistance (attending assistance: $26.1 \%$ vs. $12.9 \%, p<0.01)$ and greater frequency of upper endoscopy $(15.5 \%$ vs. $9.3 \%, p<0.01)$, and were more likely to have proactive anastomotic testing $(82.5 \%$ vs. $75.5 \%, p<0.01)$. RDS cases had longer operative duration (mean [SD], minutes: 137.1 [69] vs. 219.2 [79.1], $p<0.01$ ). Most postoperative medical and surgical complications were comparable between the two approaches (Table 3). However, LDS was associated with lower rates of venous thromboembolism $(0.4 \%$ vs. $1.3 \%, p<0.01)$, organ space infection ( $1.1 \%$ vs. $2 \%, p=$ $0.02)$, and sepsis $(0.5 \%$ vs. $1 \%, p=0.04)$. RDS had more same-day discharges ( $1 \%$ vs. $7.8 \%, p<0.01)$. These cases had lower mortality rates $(0.4 \%$ vs. $0.1 \%, p=0.03)$. The subgroup outcomes analyses of non-revised cases and DS without concurrent operation are demonstrated in different variations from the whole cohort (Tables 3 and 4). However, for isolated DS, the robotic approach had comparable rates of organ space infection $(1.2 \%$ vs. $1.7 \%, p=0.17)$ and sepsis $(0.5 \%$ vs. $0.8 \%$, $p=0.23$ ) to laparoscopy.

In the multivariable analysis, there was no difference in organ space infection ( $\mathrm{OR}=1.6, \mathrm{CI}=0.9-2.6, p=0.10)$, sepsis $(\mathrm{OR}=1.4, \mathrm{CI}=0.7-3.1, p=0.40)$, or mortality $(\mathrm{OR}=$ $0.13, \mathrm{CI}=0.02-1.0, p=0.05)$ between the two groups. While RDS increased the odds ratio for same-day discharge $(\mathrm{OR}=7.3, \mathrm{CI}=4.9-10.9, p<0.01)$, the LDS was associated with reduced odds ratio for venous thromboembolism $(\mathrm{OR}=$ 2.3, $\mathrm{CI}=1.1-4.8, p=0.02)$ (Table 5).

\section{Outcomes Over Time (2015-2018)}

The trends of patients' complexity from 2015 to 2018 are illustrated in Fig. 1. The ASA classes 3-4 and the incidence of reoperative surgery and conversion to open approach were statistically comparable between the two approaches over years.

The development of surgical site infection, sepsis/septic shock, and bleeding requiring transfusion were statistically equivalent between the two techniques in each year. Although the rate of venous thromboembolism in 2017 was greater for the RDS group ( $0.4 \%$ vs. $1.9 \%, p=0.01)$, the difference in incidence was no longer significant in the subsequent year (1.5\% vs. $1.2 \%, p=0.10)$ (Fig. 2). The operative duration was significantly longer for the robotic group across time. Hospital stay using the robotic platform was 1 day longer (median, day: 3 vs. $2, p<0.01$ ) in 2015, and these patients then had a comparable hospital stay to laparoscopy in the subsequent years (median day 2). The rates of reoperation, ICU admission, and readmission were statistically the same between the two approaches from 2015 to 2018 (Fig. 3). 
Table 1 Patients characteristics of duodenal switch for laparoscopic versus robotic approach

\begin{tabular}{|c|c|c|c|}
\hline Variable & $\begin{array}{l}\text { Laparoscopic, } \\
n=5720\end{array}$ & Robotic, $n=1515$ & $p$ value \\
\hline \multicolumn{4}{|l|}{ Age, $n(\%)$} \\
\hline $\begin{array}{l}<65 \text { years } \\
\geq 65 \text { years }\end{array}$ & $\begin{array}{l}5450(95.7 \%) \\
242(4.3 \%), N=5692\end{array}$ & $\begin{array}{l}1471(97.9 \%) \\
32(2.1 \%), N=1503\end{array}$ & $<0.01$ \\
\hline Age, mean (SD) & $44(11.4)$ & $43(10.7)$ & 0.01 \\
\hline \multicolumn{4}{|l|}{ Gender, $n(\%)$} \\
\hline $\begin{array}{l}\text { Male } \\
\text { Female }\end{array}$ & $\begin{array}{l}1542(27 \%) \\
4178(73 \%)\end{array}$ & $\begin{array}{l}399(26.3 \%) \\
1116(73.7 \%)\end{array}$ & 0.60 \\
\hline \multicolumn{4}{|l|}{ Race, $n(\%)$} \\
\hline $\begin{array}{l}\text { White } \\
\text { African American } \\
\text { Other }\end{array}$ & $\begin{array}{l}4568(79.9 \%) \\
587(10.3 \%) \\
565(9.9 \%)\end{array}$ & $\begin{array}{l}1099(72.5 \%) \\
274(18.1 \%) \\
142(9.4 \%)\end{array}$ & $<0.01$ \\
\hline Weight in kilograms, mean (SD) & $136.6(50.3)$ & $132.9(56.1)$ & 0.01 \\
\hline \multicolumn{4}{|l|}{ Body mass index (BMI), $n(\%)$} \\
\hline $\begin{array}{l}\leq 29.9 \\
30-34.9\end{array}$ & $\begin{array}{l}17(0.3 \%) \\
86(1.5 \%)\end{array}$ & $\begin{array}{l}3(0.2 \%) \\
35(2.3 \%)\end{array}$ & \multirow[t]{5}{*}{0.002} \\
\hline $35-39.9$ & $495(8.7 \%)$ & $111(7.3 \%)$ & \\
\hline $40-50$ & $2473(43.5 \%)$ & $602(39.8 \%)$ & \\
\hline $51-60$ & $1865(32.8 \%)$ & $519(34.3 \%)$ & \\
\hline$\geq 61$ & $753(13.2 \%), N=5689$ & $242(16 \%), N=1512$ & \\
\hline BMI, mean (SD) & $50.8(9.4)$ & $51.8(10.1)$ & 0.004 \\
\hline Cardiac comorbidity, $n(\%)$ & $200(3.5 \%)$ & $46(3 \%)$ & 0.40 \\
\hline Hypertension, $n(\%)$ & $2861(50 \%)$ & $737(48.6 \%)$ & 0.30 \\
\hline Hyperlipidemia, $n(\%)$ & $1315(23 \%)$ & $318(21 \%)$ & 0.10 \\
\hline Diabetes, $n(\%)$ & $1758(30.7 \%)$ & $433(28.6 \%)$ & 0.10 \\
\hline Gastroesophageal reflux disease, $n(\%)$ & $1769(30.9 \%)$ & $378(25 \%)$ & $<0.01$ \\
\hline Renal insufficiency, $n(\%)$ & $48(0.8 \%)$ & $7(0.5 \%)$ & 0.10 \\
\hline Hemodialysis, $n(\%)$ & $14(0.2 \%)$ & $3(0.2 \%)$ & 0.70 \\
\hline Deep vein thrombosis, $n(\%)$ & $139(2.4 \%)$ & $41(2.7 \%)$ & 0.50 \\
\hline Pulmonary embolism, $n(\%)$ & $106(1.9 \%)$ & $31(2 \%)$ & 0.60 \\
\hline Therapeutic anticoagulation, $n(\%)$ & $204(3.6 \%)$ & $47(3.1 \%)$ & 0.40 \\
\hline Preoperative IVC filter placement, $n(\%)$ & $81(1.4 \%)$ & $30(2 \%)$ & 0.10 \\
\hline Current smoker, $n(\%)$ & $526(9.2 \%)$ & $163(10.8 \%)$ & 0.10 \\
\hline \multicolumn{4}{|l|}{ Functional status, $n(\%)$} \\
\hline $\begin{array}{l}\text { Independent } \\
\text { Dependent }\end{array}$ & $\begin{array}{l}5560(97.2 \%) \\
160(2.8 \%)\end{array}$ & $\begin{array}{l}1507(99.5 \%) \\
8(0.5 \%)\end{array}$ & $<0.01$ \\
\hline Limited preoperative ambulation, $n(\%)$ & $238(4.2 \%)$ & $32(2.1 \%)$ & $<0.01$ \\
\hline Chronic obstructive pulmonary disease, $n(\%)$ & $134(2.3 \%)$ & $30(2 \%)$ & 0.40 \\
\hline Oxygen dependence, $n(\%)$ & $101(1.8 \%)$ & $19(1.3 \%)$ & 0.20 \\
\hline Obstructive sleep apnea, $n(\%)$ & $2363(41.3 \%)$ & $625(41.3 \%)$ & 1.00 \\
\hline Chronic steroid/immunosuppression use, $n(\%)$ & $96(1.7 \%)$ & $30(2 \%)$ & 0.40 \\
\hline Revisional surgery, $n(\%)$ & $1171(20.5 \%)$ & $323(21.3 \%)$ & 0.50 \\
\hline $\begin{array}{l}\text { Preoperative hematocrit level } \\
(\mathrm{mg} / \mathrm{dL}) \text {, median (IQR) }\end{array}$ & $41.3(5.1)$ & $40.9(4.5)$ & $<0.01$ \\
\hline $\begin{array}{l}\text { Preoperative albumin level, } \\
\text { median }(\mathrm{mg} / \mathrm{dL}), \text { median (IQR) }\end{array}$ & $3.8(4.1)$ & $3.9(0.8)$ & $<0.01$ \\
\hline
\end{tabular}

$I Q R$ interquartile range, $S D$ standard deviation, $I V C$ inferior vena cava 
Table 2 Operative features of duodenal switch for laparoscopic versus robotic approach

\begin{tabular}{|c|c|c|c|}
\hline Variable & $\begin{array}{l}\text { Laparoscopic, } \\
n=5720\end{array}$ & $\begin{array}{l}\text { Robotic, } \\
n=1515\end{array}$ & $p$ value \\
\hline \multicolumn{4}{|l|}{ ASA classification, $n(\%)$} \\
\hline I & $19(0.3 \%)$ & $0(0)$ & \multirow[t]{4}{*}{0.10} \\
\hline II & $733(12.9 \%)$ & $211(13.9 \%)$ & \\
\hline III & $4594(80.9 \%)$ & $1222(80.7 \%)$ & \\
\hline IV & $334(5.9 \%)$ & $81(5.4 \%)$ & \\
\hline \multicolumn{4}{|l|}{ Assistance level, $n(\%)$} \\
\hline Attending & $1492(26.1 \%)$ & $195(12.9 \%)$ & \multirow[t]{4}{*}{$<0.01$} \\
\hline Resident or fellow & $793(13.9 \%)$ & $591(39 \%)$ & \\
\hline Other physician assistant & $2745(48 \%)$ & $649(42.8 \%)$ & \\
\hline None & $690(12.1 \%)$ & $80(5.3 \%)$ & \\
\hline Attending level of assistance & $1492(26.1 \%)$ & $195(12.9 \%)$ & $<0.01$ \\
\hline Esophagogastroduodenoscopy, $n(\%)$ & $885(15.5 \%)$ & $141(9.3 \%)$ & $<0.01$ \\
\hline Concurrent paraesophageal hernia repair, $n(\%)$ & $495(8.7 \%)$ & $157(10.4 \%)$ & 0.04 \\
\hline Concurrent cholecystectomy, $n(\%)$ & $355(6.2 \%)$ & $213(14.1 \%)$ & $<0.01$ \\
\hline \multicolumn{4}{|l|}{ Operative duration, $n(\%)$} \\
\hline$<140 \min$ & $3471(60.8 \%)$ & $198(13.1 \%)$ & \multirow[t]{2}{*}{$<0.01$} \\
\hline$\geq 140 \mathrm{~min}$ & $2235(39.2 \%), N=5706$ & $1314(86.9 \%), N=1512$ & \\
\hline Operating time, minutes, mean (SD) & $137.1(69)$ & $219.2(79.1)$ & $<0.01$ \\
\hline Proactive testing of anastomosis, $n(\%)$ & $4616(82.5 \%), N=5597$ & $1131(75.5 \%), N=1498$ & $<0.01$ \\
\hline Unplanned conversion to open, $n(\%)$ & $65(1.1 \%)$ & $18(1.2 \%)$ & 0.90 \\
\hline
\end{tabular}

$S D$ standard deviation, ASA American Society of Anesthesiologists

\section{Discussion}

This study demonstrates that RDS may potentially provide equivalent early postoperative outcomes to LDS. Although the occurrence of thromboembolism was associated with RDS, a relative reduction in the differences in certain morbidity rates over the years between the two platforms was noted. While LDS was associated with older age, higher rates of gastroesophageal reflux, and limited preoperative ambulation, the impact of such factors was clinically insignificant. The study showed that the robotic approach may enable completion of concomitant procedures, i.e., paraesophageal hernia repair and cholecystectomy, as compared to the laparoscopy. The current analysis entailed a detailed comparison of individual outcomes along with the creation of separate adjusted models. Such an approach aids in demarcating specific clinical consequences after LDS and RDS. Given the complexity of the included cases, the evaluation of anastomotic leak surrogates and venous thromboembolism was a predetermined objective of this study. The ability to facilitate earlier recovery by the minimally invasive techniques was similarly a primary endpoint of this analysis. The available data on the outcomes of RDS were primarily derived from institutional case series $[9,11,13,15]$. Despite the previously reported safety of LDS and $\operatorname{RDS}[9,10,15]$, the literature is still lacking a comparative evaluation of the outcomes after LDS and RDS. This study was able to compare such outcomes using a national and bariatric-targeted data source.

The introduction of the robotic technology has facilitated abdominal operations $[6,7,9,11]$. The utilization of robotics in common general surgical procedures has been rising over the years [18]. The three-dimensional visual data, wristed movement, the presence of a third instrumented arm, and minimized surgeon fatigue are known to be some advantages of the technique. However, the longer operating time [ [6]] and increased costs [18] in the setting of unclear clinical benefits may prevent the widespread adoption of the technology. Furthermore, it is still unknown whether the robotic platform has improved the performance of duodenal switch surgery when compared to conventional laparoscopy. Nevertheless, as expertise and efficiency with the robotic duodenal switch continue to improve, studies will be necessary to reassess these differences.

Abdominal sepsis from anastomotic leak is associated with significant morbidity, mortality, and resource utilization [19]. The risk is greater for severely obese and comorbid patients [20], the standard population of duodenal switch [1]. Prior institutional reports found anastomotic leak to be 9\% [8] and $8 \%$ [9] for laparoscopic and robotic duodenal switch, respectively. However, these were small case series. Others reported the rates to be around $1 \%$ or less for both approaches [10,12]. Consistently, a national study found the rates of anastomotic 
Table 3 Thirty-day postoperative outcomes of duodenal switch for laparoscopic versus robotic approach

\begin{tabular}{|c|c|c|c|c|c|c|}
\hline \multirow[t]{2}{*}{ Variable } & \multicolumn{3}{|l|}{ All DS cases } & \multicolumn{3}{|c|}{ Non-revised DS cases only } \\
\hline & $\begin{array}{l}\text { Laparoscopic, } \\
n=5720\end{array}$ & $\begin{array}{l}\text { Robotic, } \\
n=1515\end{array}$ & $p$ value & $\begin{array}{l}\text { Laparoscopic, } \\
n=4549\end{array}$ & $\begin{array}{l}\text { Robotic, } \\
n=1192\end{array}$ & $p$ value \\
\hline Acute renal failure, $n(\%)$ & $17(0.3 \%)$ & $2(0.1 \%)$ & 0.30 & $13(0.3 \%)$ & $2(0.2 \%)$ & 0.45 \\
\hline Progressive renal insufficiency, $n(\%) \mathrm{y}$ & $11(0.2 \%)$ & $6(0.4 \%)$ & 0.10 & $8(0.2 \%)$ & $5(0.4 \%)$ & 0.12 \\
\hline Dehydration requiring treatment, $n(\%)$ & $193(4 \%), N=4809$ & $50(4 \%), N=1244$ & 1.00 & $163(4.3 \%)$ & $43(4.5 \%)$ & 0.90 \\
\hline \multicolumn{7}{|l|}{ Number of dehydration episodes, $n(\%)$} \\
\hline $\begin{array}{l}\text { Once } \\
\geq 2 \text { episodes }\end{array}$ & $\begin{array}{l}150(3.1 \%) \\
28(0.6 \%), N=4794\end{array}$ & $\begin{array}{l}40(3.2 \%) \\
8(0.6 \%), N=1242\end{array}$ & 1.00 & $\begin{array}{l}128(3.4 \%) \\
20(0.5 \%)\end{array}$ & $\begin{array}{l}35(3.6 \%) \\
6(0.6 \%)\end{array}$ & 0.90 \\
\hline Cardiac arrest, $n(\%)$ & $6(0.1 \%)$ & $2(0.1 \%)$ & 0.80 & $3(0.1 \%)$ & $1(0.1 \%)$ & 0.83 \\
\hline Myocardial infarction, $n(\%)$ & $4(0.1 \%)$ & $1(0.1 \%)$ & 1.00 & $4(0.1 \%)$ & $1(0.1 \%)$ & 0.10 \\
\hline Stroke, $n(\%)$ & $3(0.1 \%)$ & $0(0 \%)$ & 0.40 & $3(0.1 \%)$ & $0(0 \%)$ & 0.40 \\
\hline Coma, $n(\%)$ & $1(0 \%)$ & $0(0 \%)$ & 0.60 & - & - & - \\
\hline Wound disruption, $n(\%)$ & $18(0.3 \%)$ & $1(0.1 \%)$ & 0.10 & $14(0.3 \%)$ & $1(0.1 \%)$ & 0.20 \\
\hline Superficial surgical site infection, $n(\%)$ & $35(0.6 \%)$ & $10(0.7 \%)$ & 0.80 & $25(0.5 \%)$ & $9(0.8 \%)$ & 0.41 \\
\hline Deep surgical site infection, $n(\%)$ & $15(0.3 \%)$ & $3(0.2 \%)$ & 0.60 & $6(0.1 \%)$ & $3(0.3 \%)$ & 0.35 \\
\hline Organ space surgical site infection, $n(\%)$ & $67(1.1 \%)$ & $30(2 \%)$ & 0.02 & $46(1 \%)$ & $23(1.9 \%)$ & 0.01 \\
\hline Any surgical site infections, $n(\%)$ & $116(2 \%)$ & $43(2.8 \%)$ & 0.10 & $76(1.7 \%)$ & $35(2.9 \%)$ & 0.01 \\
\hline Sepsis, $n(\%)$ & $30(0.5 \%)$ & $15(1 \%)$ & 0.04 & $17(0.4 \%)$ & $13(1.1 \%)$ & 0.002 \\
\hline Septic shock, $n(\%)$ & $17(0.3 \%)$ & $5(0.3 \%)$ & 0.80 & $13(0.3 \%)$ & $4(0.3 \%)$ & 0.80 \\
\hline Pneumonia, $n(\%)$ & $30(0.5 \%)$ & $6(0.4 \%)$ & 0.50 & $23(0.5 \%)$ & $6(0.5 \%)$ & 1.00 \\
\hline Ventilator dependent, $n(\%)$ & $13(0.2 \%)$ & $8(0.5 \%)$ & 0.10 & $9(0.2 \%)$ & $6(0.5 \%)$ & 0.10 \\
\hline Unplanned reintubation, $n(\%)$ & $24(0.4 \%)$ & $10(0.7 \%)$ & 0.20 & $19(0.4 \%)$ & $6(0.5 \%)$ & 0.70 \\
\hline Venous thrombosis requiring treatment, $n(\%)$ & $14(0.2 \%)$ & $11(0.7 \%)$ & 0.01 & $10(0.2 \%)$ & $7(0.6 \%)$ & 0.04 \\
\hline Pulmonary embolism, $n(\%)$ & $13(0.2 \%)$ & $10(0.7 \%)$ & 0.01 & $11(0.2 \%)$ & $6(0.5 \%)$ & 0.14 \\
\hline Venous thromboembolism, $n(\%)$ & $25(0.4 \%)$ & $19(1.3 \%)$ & $<0.01$ & $19(0.4 \%)$ & $11(0.9 \%)$ & 0.03 \\
\hline Peripheral nerve injury, $n(\%)$ & $0(0 \%)$ & $1(0.1 \%)$ & 0.10 & $0(0 \%)$ & $1(0.1 \%)$ & 0.10 \\
\hline Bleeding requiring transfusion, $n(\%)$ & $41(0.7 \%)$ & $14(0.9 \%)$ & 0.40 & $34(0.7 \%)$ & $11(0.9 \%)$ & 0.54 \\
\hline Urinary tract infection, $n(\%)$ & $35(0.6 \%)$ & $11(0.7 \%)$ & 0.60 & $24(0.5 \%)$ & $9(0.8 \%)$ & 0.34 \\
\hline ICU admission, $n(\%)$ & $135(2.4 \%)$ & $37(2.4 \%)$ & 0.90 & $99(2.2 \%)$ & $26(2.2 \%)$ & 1.00 \\
\hline Reoperation, $n(\%)$ & $207(3.6 \%)$ & $67(4.4 \%)$ & 0.10 & $157(3.5 \%)$ & $48(4 \%)$ & 0.34 \\
\hline Readmission, $n(\%)$ & $390(6.8 \%)$ & $125(8.3 \%)$ & 0.10 & $302(6.6 \%)$ & $94(7.9 \%)$ & 0.13 \\
\hline \multicolumn{7}{|l|}{ Postoperative length of stay, $n(\%)$} \\
\hline $\begin{array}{l}<24 \mathrm{~h} \\
\geq 24 \mathrm{~h}\end{array}$ & $\begin{array}{l}55(1 \%) \\
5997(99 \%)\end{array}$ & $\begin{array}{l}118(7.8 \%) \\
1397(92.2 \%)\end{array}$ & $<0.01$ & $\begin{array}{l}43(0.9 \%) \\
4506(99.1 \%)\end{array}$ & $\begin{array}{l}91(7.6 \%) \\
1101(92.4 \%)\end{array}$ & $<0.01$ \\
\hline Extended care after discharge, $n(\%)$ & $37(0.6 \%)$ & $10(0.7 \%)$ & 0.80 & $25(0.6 \%)$ & $6(0.5 \%)$ & 0.84 \\
\hline Death, $n(\%)$ & $25(0.4 \%)$ & $1(0.1 \%)$ & 0.03 & $21(0.5 \%)$ & $0(0 \%)$ & 0.02 \\
\hline
\end{tabular}

$I C U$ intensive care unit, $D S$ duodenal switch

leak after Roux-en-Y gastric bypass to be below 1\% [21]. However, the MBSAQIP does not capture anastomotic leak as a postoperative complication. In this study, the robotic group had higher rates of organ space infection ( $2 \%$ vs. $1.1 \%, p=0.02)$ and sepsis ( $1.0 \%$ vs. $0.5 \%, p=0.04)$ in the univariable analysis. The subgroup analysis of primary, nonrevised DS demonstrated similar variations between the two approaches (Table 3). On the other hand, the occurrence of organ space and systemic infections were indifferent between robotic and laparoscopic groups after an isolated DS (Table 4). These findings were consistent with the results from the adjusted multivariable analyses (Table 5). Such equivalence in postoperative wound and systemic infections between the two approaches was previously reported for gastric bypass $[6,7$, 21]. The comparability in these major complications may explain the insignificant difference in 30-day mortality in the current adjusted model. However, intraoperative mortality was captured under the same variable. Intraoperative death 
Table 4 Thirty-day postoperative outcomes of minimally invasive duodenal switch without concurrent operations
Table 5 Multivariable analysis of the association between robotic duodenal switch and outcomes when compared to laparoscopy

\begin{tabular}{|c|c|c|c|}
\hline Variable & $\begin{array}{l}\text { Laparoscopic, } \\
n=4871\end{array}$ & $\begin{array}{l}\text { Robotic, } \\
n=1145\end{array}$ & $p$ value \\
\hline Acute renal failure, $n(\%)$ & $14(0.3 \%)$ & $2(0.2 \%)$ & 0.50 \\
\hline Progressive renal insufficiency, $n(\%) \mathrm{y}$ & $10(0.2 \%)$ & $4(0.3 \%)$ & 0.40 \\
\hline Dehydration requiring treatment, $n(\%)$ & $169(4.1 \%)$ & $36(3.8 \%)$ & 0.60 \\
\hline \multicolumn{4}{|l|}{ Number of dehydration episodes, $n(\%)$} \\
\hline $\begin{array}{l}\text { Once } \\
\geq 2 \text { episodes }\end{array}$ & $\begin{array}{r}131(3.2 \%) \\
24(0.6 \%)\end{array}$ & $\begin{array}{l}29(3 \%) \\
6(0.6 \%)\end{array}$ & 1.00 \\
\hline Cardiac arrest, $n(\%)$ & $5(0.1 \%)$ & $2(0.2 \%)$ & 0.50 \\
\hline Myocardial infarction, $n(\%)$ & $4(0.1 \%)$ & $1(0.1 \%)$ & 1.00 \\
\hline Stroke, $n(\%)$ & $3(0.1 \%)$ & $0(0 \%)$ & 0.40 \\
\hline Coma, $n(\%)$ & $1(0 \%)$ & $0(0 \%)$ & 0.60 \\
\hline Wound disruption, $n(\%)$ & $18(0.4 \%)$ & $1(0.1 \%)$ & 0.13 \\
\hline Superficial surgical site infection, $n(\%)$ & $26(0.5 \%)$ & $10(0.9 \%)$ & 0.18 \\
\hline Deep surgical site infection, $n(\%)$ & $14(0.3 \%)$ & $1(0.1 \%)$ & 0.22 \\
\hline Organ space surgical site infection, $n(\%)$ & $60(1.2 \%)$ & $20(1.7 \%)$ & 0.17 \\
\hline Any surgical site infections, $n(\%)$ & $99(2 \%)$ & $31(2.7 \%)$ & 0.16 \\
\hline Sepsis, $n(\%)$ & $24(0.5 \%)$ & $9(0.8 \%)$ & 0.23 \\
\hline Septic shock, $n(\%)$ & $13(0.3 \%)$ & $4(0.3 \%)$ & 0.60 \\
\hline Pneumonia, $n(\%)$ & $25(0.5 \%)$ & $3(0.3 \%)$ & 0.26 \\
\hline Ventilator dependent, $n(\%)$ & $12(0.2 \%)$ & $4(0.3 \%)$ & 0.54 \\
\hline Unplanned reintubation, $n(\%)$ & $21(0.4 \%)$ & $7(0.6 \%)$ & 0.42 \\
\hline Venous thrombosis requiring treatment, $n(\%)$ & $14(0.3 \%)$ & $10(0.9 \%)$ & 0.01 \\
\hline Pulmonary embolism, $n(\%)$ & $11(0.2 \%)$ & $9(0.8 \%)$ & 0.01 \\
\hline Venous thromboembolism, $n(\%)$ & $23(0.5 \%)$ & $17(1.5 \%)$ & $<0.01$ \\
\hline Peripheral nerve injury, $n(\%)$ & $0(0 \%)$ & $1(0.1 \%)$ & 0.20 \\
\hline Bleeding requiring transfusion, $n(\%)$ & $34(0.7 \%)$ & $11(1 \%)$ & 0.40 \\
\hline Urinary tract infection, $n(\%)$ & $33(0.7 \%)$ & $8(0.7 \%)$ & 0.90 \\
\hline ICU admission, $n(\%)$ & $119(2.4 \%)$ & $27(2.4 \%)$ & 0.90 \\
\hline Reoperation, $n(\%)$ & $172(3.5 \%)$ & $43(3.8 \%)$ & 0.71 \\
\hline Readmission, $n(\%)$ & $339(7 \%)$ & $92(8 \%)$ & 0.20 \\
\hline \multicolumn{4}{|l|}{ Postoperative length of stay, $n(\%)$} \\
\hline $\begin{array}{l}<24 \mathrm{~h} \\
\geq 24 \mathrm{~h}\end{array}$ & $\begin{array}{c}49(1 \%) \\
4822(99 \%)\end{array}$ & $\begin{array}{c}64(5.6 \%) \\
1081(94.4 \%)\end{array}$ & $<0.01$ \\
\hline Extended care after discharge, $n(\%)$ & $31(0.6 \%)$ & $7(0.6 \%)$ & 0.92 \\
\hline Death, $n(\%)$ & $19(0.4 \%)$ & $1(0.1 \%)$ & 0.10 \\
\hline
\end{tabular}

$I C U$ intensive care unit

\begin{tabular}{llcr}
\hline Variable & Odds ratio (OR) & Confidence interval (CI) & $p$ value \\
\hline Organ space surgical site infection & 1.6 & $0.9-2.6$ & 0.10 \\
Sepsis & 1.4 & $0.7-3.1$ & 0.40 \\
Venous thromboembolism & 2.3 & $1.1-4.8$ & 0.02 \\
Early discharge $(\operatorname{LOS}<24 \mathrm{~h})$ & 7.3 & $4.9-10.9$ & $<0.01$ \\
Mortality & 0.13 & $0.02-1.0$ & 0.05 \\
\hline
\end{tabular}

Adjusted covariates: age ( $<65$ vs. $\geq 65$ ), race, gastroesophageal reflux disease, functional dependence, limited preoperative ambulation, body mass index, preoperative hematocrit, and albumin levels, intraoperative level of assistance, esophagogastroduodenoscopy, paraesophageal hernia repair, cholecystectomy, operative duration $(<$ $140 \mathrm{vs.} \geq 140 \mathrm{~min}$ ) and anastomosis testing

LOS length of stay 
Fig. 1 Patients complexity for laparoscopic and robotic duodenal switch over time (20152018)

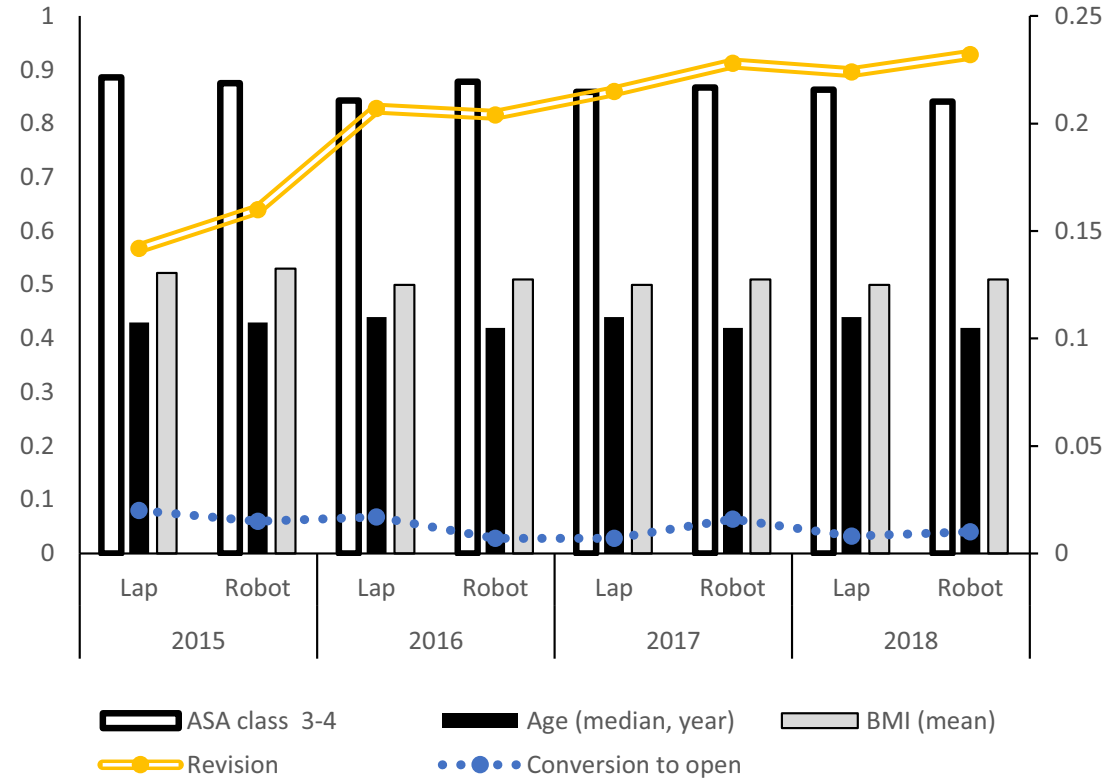

may potentially be influenced by the patient pre-existing conditions rather than the direct impact of the surgical technique. Prior institutional studies found mortality rates to be similarly low after both LDS and RDS [9, 10, 15].

Postoperative venous thromboembolism is relatively common in bariatric patients [22]. Duodenal switch has been reported as an independent predictor for the complication [23]. Halawani et al. evaluated 662 LDS and RDS and reported the overall rate to be $2.4 \%$ [24]. This is consistent with the incidence of the complication from an earlier institutional report of laparoscopic duodenal switch [14]. However, recent reports of RDS [13] and minimally invasive gastric bypass [21] found the occurrence of venous thrombosis to be less than $1 \%$. It is possible that the improved efficiency in duodenal switch surgery was the cause of such a shift over time. Similarly, the rates were $0.4 \%$ and $1.3 \%$ for LDS and RDS respectively in current study. Despite the comparable preoperative risk of venous thromboembolic events, RDS was independently associated with the complication in the adjusted model. The development of VTE continued to be higher for the robotic approach in subgroup analysis of non-revised operations. Although the rate of venous thromboembolism was lower
Fig. 2 Outcomes trends for laparoscopic and robotic duodenal switch over time (20152018)

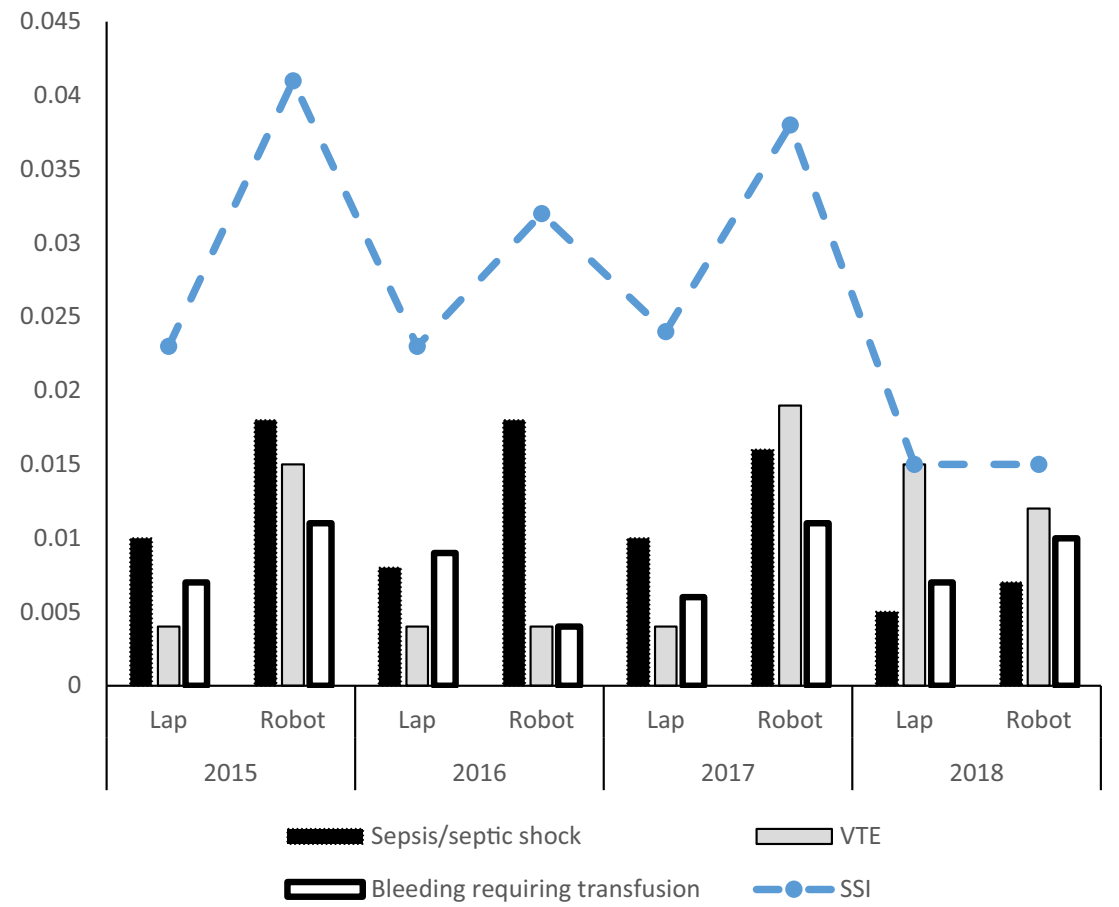


Fig. 3 Resource utilization for laparoscopic and robotic duodenal switch over time (20152018)

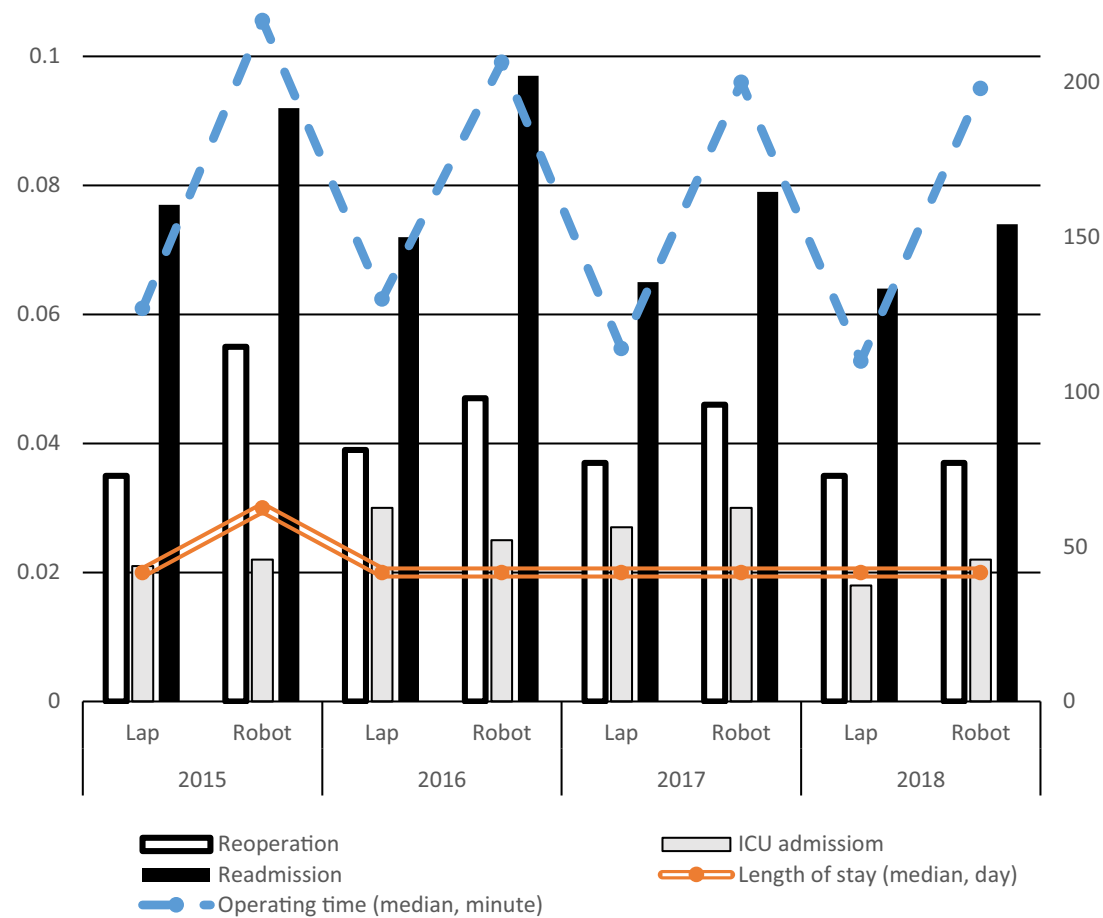

with no concurrent operations, this was still statistically higher in the robotic group. While the RDS group had higher BMI, such a variation in VTE was likely due to the longer RDS operative duration. In this study, RDS had a lower level of intraoperative assistance. However, the level of assistance was previously found to have an insignificant impact on operative duration [25]. However, the subgroup analysis by years illustrated the rates to be fluctuating. While the robotic approach had a significantly greater venous thromboembolism in 2017 ( $0.4 \%$ vs. $1.9 \%, p=0.001)$, it became equivalent to laparoscopy in the last year, $2018(1.5 \%$ vs. $1.2 \%, p=0.1)$. This is associated with, and possibly a result of, a relative reduction in operative time for RDS over time. While the smaller robotic sample size could explain the variation, the decreasing rates of venous thromboembolic events may suggest increasing efficiency in the utilization of the robotic platform from 2015 to 2018.

Previous single institutional series reported hospital length of stay to be 4-5.5 and 2.7-4.6 days for LDS $[8,14]$ and RDS, $[11,13]$ respectively. In addition to the limited sample sizes, most of these analyses were from the earlier experience with the minimally invasive duodenal switch. We compared hospital stay between the two techniques in every year included in the study. Except in 2015 (median day: 3 vs. $2, p<0.01$ for RDS and LDS respectively), the robotic technology was able to have a comparable overall length of stay (2 days) to laparoscopy. Despite the higher rates of concurrent operations with RDS, the technique was associated with the discharge on the same day after surgery in the multivariable analysis. The subgroup analyses of non-revised cases and those without concurrent operations demonstrated higher earlier discharges with the robotic approach. This was consistent with the adjusted analysis. The ability of robotics to discharge patients earlier when compared to conventional approaches has previously been noted for other bariatric operations [7]. Despite the previously reported increased morbidity after same-day discharge [26], RDS was associated with comparable clinical outcomes to LDS. However, the current subgroup analysis showed a comparable median LOS between the two approaches over the recent years. It is possible that most of the robotic cases were performed at high-volume institutions where a strict early discharge policy is implemented. In addition, the potential effect of selection bias could not be excluded with higher percentage of earlier recovery with robotics.

Trends in outcomes over time with each surgical platform had not been previously characterized. In this study, we were able to track the changes in outcomes between LDS and RDS over years. While the patients' complexity parameters (Fig. 1) were equivalent between the two approaches, a relative reduction in the difference in certain complications was noted. This included the difference in the development of surgical site infection and sepsis/septic shock (Fig. 2). The differences in reoperation and ICU admission and readmission were statistically insignificant between the two approaches over years. Our findings of overall equilibrating outcomes trends in LDS vs. RDS over time may be related to the increasingly 
more frequent use of the robotic platform across the nation in the recent years, resulting in greater surgeon experience, safety, and efficiency.

This study is the first multicenter comparative assessment for LDS and RDS; however, several limitations of our analysis should be noted. The retrospective nature of the study and the lack of clinically important variables, such as anastomotic leak, present limitations due to study design, recording bias, and researcher interpretation. The availability of a standardized variable for anastomotic leak would provide a better understanding of the incidence, severity, and consequence of the complication. The details regarding previous operations in revisional cases (gastric banding vs. sleeve gastrectomy vs. Roux-en-Y gastric bypass) were not captured by the MBSAQIP. Although the primary CPT code includes partial gastrectomy, the presence of staged duodenal switch was not defined by the database, leading to potential patients' heterogeneity. This study included duodenal switch operations with duodenoileostomy and ileoileostomy. It is possible that the various types of bariatric conversions and duodenal switch operations are associated with different perioperative courses. Despite the standardization of variables, the MBSAQIP captures postoperative sepsis using the traditional definition, rather than the Sepsis-3 definition. Although the perioperative risk of venous thrombosis and BMI were eventually adjusted, the use of post-discharge VTE prophylaxis was unidentifiable. The impact of the bariatric caseload on postoperative outcomes is well established [27]. However, adjusting groups for the hospital or provider volume of minimally invasive cases was not feasible using the data source. Given the low observations of certain outcomes, the overfitting of the adjusted models remains a possibility in this study.

\section{Conclusion}

Robotic duodenal switch may provide comparable short-term outcomes to laparoscopy, except for higher risk of venous thromboembolism with the newer technology. The difference in the development of venous thromboembolism between the two approaches has been decreasing over time. RDS may reduce the need for intraoperative attending assistance and length of stay in select cases while demonstrating equivalent complications to LDS. The recent trends suggest a gradual decrease in the outcomes variations between the two platforms.

\section{Compliance with Ethical Standards}

Conflict of Interest The authors declare that they have no conflict of interest.

\section{References}

1. Prachand VN, Davee RT, Alverdy JC. Duodenal switch provides superior weight loss in the super-obese $(B M I>$ or $=50 \mathrm{~kg} / \mathrm{m} 2)$ compared with gastric bypass. Ann Surg. 2006;244(4):611-9.

2. Buchwald H, Kellogg TA, Leslie DB, et al. Duodenal switch operative mortality and morbidity are not impacted by body mass index. Ann Surg. 2008;248(4):541-8.

3. Wittgrove AC, Clark GW, Tremblay LJ. Laparoscopic gastric bypass, Roux-en-Y: preliminary report of five cases. Obes Surg. 1994;4(4):353-7.

4. Nguyen NT, Ho HS, Palmer LS, et al. A comparison study of laparoscopic versus open gastric bypass for morbid obesity. J Am Coll Surg. 2000;191(2):149-55. discussion 155-7

5. DeMaria EJ, Pate V, Warthen M, et al. Baseline data from American Society for Metabolic and Bariatric Surgery-designated Bariatric Surgery Centers of Excellence using the Bariatric Outcomes Longitudinal Database. Surg Obes Relat Dis. 2010;6(4):347-55.

6. Rogula T, Koprivanac M, Janik MR, et al. Does robotic Roux-en-Y Gastric bypass provide outcome advantages over standard laparoscopic approaches? Obes Surg. 2018;28(9):2589-96.

7. Hagen ME, Pugin F, Chassot G, et al. Reducing cost of surgery by avoiding complications: the model of robotic Roux-en-Y gastric bypass. Obes Surg. 2012;22(1):52-61.

8. Dapri G, Cadière GB, Himpens J. Laparoscopic conversion of adjustable gastric banding and vertical banded gastroplasty to duodenal switch. Surg Obes Relat Dis. 2009;5(6):678-83.

9. Sudan R, Puri V, Sudan D. Robotically assisted biliary pancreatic diversion with a duodenal switch: a new technique. Surg Endosc. 2007;21(5):729-33.

10. Kim W, Gagner M, Kini S, et al. Laparoscopic vs. open biliopancreatic diversion with duodenal switch: a comparative study. J Gastrointest Surg. 2003;7(4):552-7. https://doi.org/10. 1016/S1091-255X(02)00149-X.

11. Sudan R, Podolsky E. Totally robot-assisted biliary pancreatic diversion with duodenal switch: single dock technique and technical outcomes. Surg Endosc. 2015;29(1):55-60.

12. Antanavicius G, Rezvani M, Sucandy I. One-stage robotically assisted laparoscopic biliopancreatic diversion with duodenal switch: analysis of 179 patients. Surg Obes Relat Dis. 2015;11(2): 367-71.

13. Antanavicius G, Katsichtis T, Alswealmeen W, et al. Three hundred four robotically assisted biliopancreatic diversion with duodenal switch operations with gradual robotic approach implementation: short-term outcomes, complication profile, and lessons learned. Obes Surg. 2020; https://doi.org/10.1007/s11695-020-04764-1.

14. Ren CJ, Patterson E, Gagner M. Early results of laparoscopic biliopancreatic diversion with duodenal switch: a case series of 40 consecutive patients. Obes Surg. 2000;10(6):514-23. discussion 524

15. Sudan R, Desai S. Conversion of laparoscopic adjustable gastric band to robot-assisted laparoscopic biliopancreatic diversion with duodenal switch. Surg Obes Relat Dis. 2011;7(4):546-7.

16. Berger E, Clements R, Morton J, et al. The impact of different surgical techniques on outcomes in laparoscopic sleeve gastrectomies: the first report from the metabolic and bariatric surgery accreditation and quality improvement program (MBSAQIP). Ann Surg. 2016;264(3):464-73. https://doi.org/10.1097/SLA. 0000000000001851 .

17. Leepalao M, Arredondo D, Speights F, et al. Same-day discharge on laparoscopic Roux-en-Y gastric bypass patients: an outcomes review. Surg Endosc. 2020;34(8):3614-7. https://doi.org/10.1007/ s00464-019-07139-5. 
18. Armijo P, Pagkratis S, Boilesen E, et al. Growth in robotic-assisted procedures is from conversion of laparoscopic procedures and not from open surgeons' conversion: a study of trends and costs. Surg Endosc. 2018;32(4):2106-13. https://doi.org/10.1007/s00464-0175908-z.

19. Arteaga JR, Huerta S, Livingston EH. Management of gastrojejunal anastomotic leaks after Roux-en-Y gastric bypass. Am Surg. 2002;68(12):1061-5.

20. Fernandez Jr AZ, DeMaria EJ, Tichansky DS, et al. Experience with over 3,000 open and laparoscopic bariatric procedures: multivariate analysis of factors related to leak and resultant mortality. Surg Endosc. 2004;18(2):193-7.

21. Sebastian R, Howell M, Chang K, et al. Robot-assisted versus laparoscopic Roux-en-Y gastric bypass and sleeve gastrectomy: a propensity score-matched comparative analysis using the 2015-2016 MBSAQIP database. Surg Endosc. 2019;33(5):1600-12. https:// doi.org/10.1007/s00464-018-6422-7.

22. Moussa O, Ardissino M, Tang A, et al. Long-term impact of bariatric surgery on venous thromboembolic risk: a matched cohort study. Ann Surg. 2019. https://doi.org/10.1097/SLA. 0000000000003750 .
23. Finks JF, English WJ, Carlin AM, et al. Predicting risk for venous thromboembolism with bariatric surgery: results from the Michigan Bariatric Surgery Collaborative. Ann Surg. 2012;255(6):1100-4.

24. Halawani HM, Ripley-Hager CF, Naglak MC, et al. Venous thromboembolism after laparoscopic or robotic biliopancreatic diversion with duodenal switch. Ninety-days outcome of a 10 years' experience. Surg Obes Relat Dis. 2017;13(12):1984-9.

25. Moore MD, Afaneh C, Gray KD, et al. The impact of the robotic platform on assistant variability in complex gastrointestinal surgery. J Surg Res. 2017;219:98-102.

26. Inaba CS, Koh CY, Sujatha-Bhaskar S, et al. Same-day discharge after laparoscopic Roux-en-Y Gastric bypass: an analysis of the metabolic and bariatric surgery accreditation and quality improvement program database. J Am Coll Surg. 2018;226(5):868-73. https://doi.org/10.1016/j.jamcollsurg.2018.01.049.

27. Zevin B, Aggarwal R, Grantcharov TP. Volume-outcome association in bariatric surgery: a systematic review. Ann Surg. 2012;256(1):60-71. https://doi.org/10.1097/SLA. $0 \mathrm{~b} 013 \mathrm{e} 3182554 \mathrm{c} 62$.

Publisher's Note Springer Nature remains neutral with regard to jurisdictional claims in published maps and institutional affiliations. 